Proc. Indian Acad. Sci. (Chem. Sci.), Vol. 105, No. 6, December 1993, pp. 405-419.

(C) Printed in India.

\title{
Applied photochemistry in dental science
}

\author{
LARS-ÅKE LINDÉN \\ Department of Dental Materials, Karolinska Institute, Royal Institute of Medicine, Box \\ 4064, S-141 04 Huddinge, Stockholm, Sweden
}

\begin{abstract}
This paper presents a short review of the most important problems involved in the photocuring of dental polymer materials, such as a choice of photoinitiating system (mainly based on camphorquinone-amines), kinetics of polymer conversion, depth of curing, shrinkage etc., and also discusses problems with damage of photocured surfaces by chemical, biological, and mechanical degradation.
\end{abstract}

Keywords. Dental materials; photocuring of polymeric materials; damage to photocured surfaces; photoinitiating system.

During the last two decades, the production of polymers and plastics (composite resins) for dental applications has increased rapidly. These materials are inexpensive, easy to use, and have recently been applied to replace amalgams and other traditional dental materials such as gold, cements, and ceramics. However, they must meet strict demands such as physico-chemical (dimensional stability, strength, craze, and wear resistance), chemical (resistance to hydrolytic and enzymatic degradation), and biological (resistance to biodegradation by microorganisms), toxicological and allergiological demands.

The most common group of dental polymers are polymethacrylates based on mono-, di-, oligomonomers and oligomers. They are used in dentistry for processing denture bases, crown and bridge prosthetics, artificial teeth, orthodontic appliances, and for restorative dentistry (filling materials). For these applications, liquid monomer (modified methyl methacrylates), prepolymerized poly(methyl methacrylates) and cross-linking monomers based on di-, or tri-functional vinyl monomers (e.g ethyleneglycol dimethacrylate or butenediol dimethacrylate) are polymerized by free radical or ionic initiators. More than 100 commercially produced monomers have been used by private companies to prepare dental composites. Some examples are listed in table 1.

Polymerization of dental composites in the oral cavity is restricted by biological demands and should not exceed temperatures of $50^{\circ} \mathrm{C}$. This condition eliminates almost all thermally initiated free-radical polymerizations. The soft tissues in the oral cavity are very sensitive to the strong acids formed in some ionic polymerization systems that can be polymerized at room temperature. All of these problems can be overcome by the use of photocuring.

Most common photoinitiators such as analogues of benzoin methyl ethers undergo photofragmentation with the formation of free radicals when exposed to UV irradiation below $400 \mathrm{~nm}$. Use of this type of radiation is restricted in dental applications, because of carcenogenic and photoallergic effects, and the risk of tissue burning 
Table 1. Examples of monomers used in photocured resins.

$$
\begin{gathered}
\mathrm{CH}_{2}-\mathrm{CH}-\stackrel{\mathrm{O}}{\mathrm{C}}-\mathrm{OC}_{2} \mathrm{H}_{3} \\
\text { Ethyl acrylate } \\
\mathrm{CH}_{3} 、 \mathrm{~N}_{1}^{-\mathrm{CH}_{3}} \\
\mathrm{CH}_{2}=\underset{\mathrm{C}}{\mathrm{C}} \mathrm{OCH}_{3}
\end{gathered}
$$

$\mathrm{N}, \mathrm{N}$ - dimethylamino methacrylate

$$
\mathrm{CH}_{2}=\stackrel{\mathrm{C}_{3}}{\mathrm{C}-\mathrm{COOCH}_{2} \mathrm{CH}_{2} \mathrm{~N}} \underset{\mathrm{CH}_{3}}{\mathrm{CH}_{3}}
$$

2 - dimethylaminoethyl methacrylate

$$
\begin{gathered}
\mathrm{CH}_{2}-\mathrm{CH}-\stackrel{\mathrm{O}}{\mathrm{C}}-\mathrm{OCH}_{2}-\left(\mathrm{CH}_{2}\right)_{4}-\mathrm{CH}_{2} \mathrm{O}-\mathrm{O}-\mathrm{CH}-\mathrm{CH}_{2} \\
\text { (HDDA) } \\
\text { (HDedial diacrylate }
\end{gathered}
$$

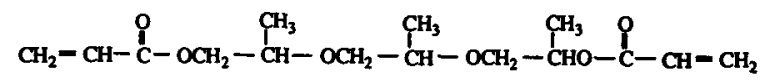

Tripropyleneglycol diacrylate (TPGDA)<smiles>CC(C)C(=O)OCC(CO)(CO)C(=O)OC(=O)C(C)C</smiles>

Pentaerythriol triacrylate

(PETA)<smiles>CCC(CC)(CO)CC(=O)OC(=O)C(C)C(C)C(=O)O</smiles>

Trimethylolpropane triacrylate (TMPTA)<smiles>CCCCCOC(=O)OCCOCCOC(=O)C(C)C</smiles>

(TEGDMA)

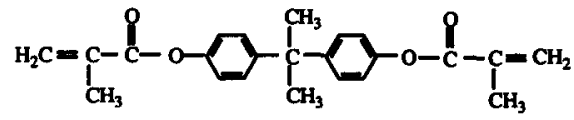

Bis (phenol A - dimethacrylate) (bis- DMA)<smiles>C=C(C)C(=O)OCC(O)COc1ccc(C(C)(C)C)cc1OCC(O)CC(O)CO[C@H](C)C(=O)OCC(=O)C(C)C</smiles>

Bis (phenol A - diglycidylether dimethacrylate) (bis - GMA) 
Table 1. (Continued)<smiles>CC(COCC(C)OC(=O)C(C)C)OCC(C)OC(=O)C(C)C</smiles>

Bis (phenol A - propylether dimethacrylate)<smiles>CC(C)C(=O)OCOCCOC(=O)C(C)(C)COOCOOC(=O)C(C)C</smiles>

Bis (phenol A - $-\underline{n}$ alkylether dimethacrylate)

( $\underline{n}=2: \underline{\text { bis }}-\bar{E} M A, \underline{n}=3: \underline{\text { bis }}-\mathrm{PMA})$

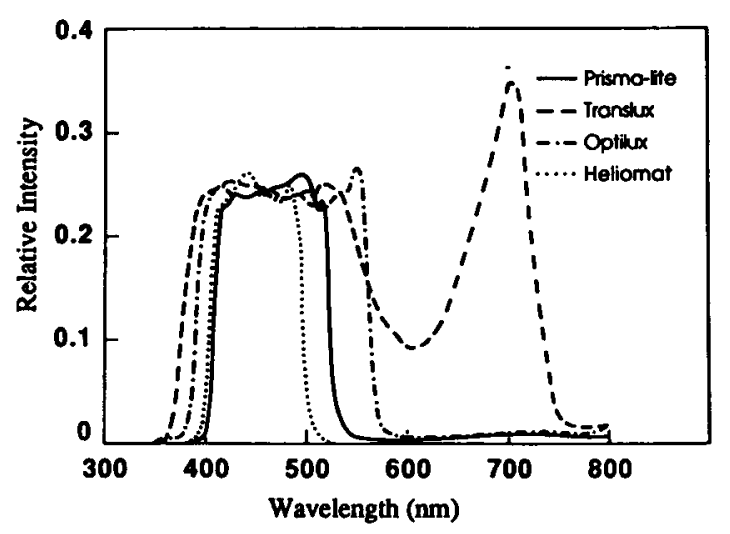

Figure 1. Emission spectra from typical commercial lamps designed for intra-oral photocuring.

(Birdsell et al 1977). The only light irradiation allowed for application in the oral cavity is at wavelengths over $400 \mathrm{~nm}$ (Cook 1982).

Most commercially produced irradiation-lamp devices operate with blue light at a maximum of $470 \mathrm{~nm}$ (figure 1). This causes a number of problems in finding a photoinitiating system which is effective in this spectral region, that is, which absorbs blue light.

The most common photoinitiating system used in dental applications consists of camphorquinone (which is a diketone, table 2) and different amines (coinitiators) such as $\mathbf{N}, \mathbf{N}$-3,5-tetra-methylaniline, $\mathrm{N}, \mathrm{N}$-dimethylamino phenethyl alcohol, $\mathbf{N}, \mathbf{N}$ dimethylaminoethyl methacrylate (table 3) (Sheela 1991; Cook 1992).

Camphorquinone has a maximum absorbtion at $468 \mathrm{~nm}$ (figure 2), and its excited triplet state reacts with amine to form an exciplex (excited state complex) The exciplex is a short-lived species and it fragments into camphorquinone pinacol radical (A) and amine radical (B) according to reactions 1 and 2 (scheme 1) (Dietliker 1991).

Camphorquinone pinacol radical $(\mathrm{A})$ is deactivated by hydrogen abstraction and/or dimerization reaction and cannot initiate polymerization, whereas the amine radical (B) is responsible for the initiation of polymerization. 
Table 2. Examples of di-ketones (photoinitiators) used in photocured resins.<smiles>CC(=O)[C@@H](C)O</smiles><smiles>O[C@@H](c1ccccc1)[C@H](O)c1ccccc1</smiles><smiles>O[C@H]1c2cccc3cccc(c23)[C@H]1O</smiles>

Acenaphtenequinone<smiles>CC12CCC(C(=O)C1=O)C2(C)C</smiles>

Camphorquinone

Table 3. Examples of amine coinitiators used in photocured resins.<smiles>Cc1ccc(N(C)C)cc1</smiles>

$\mathrm{N}, \mathrm{N}$-dimethyl-p-toluidine<smiles>CN(C)c1ccc(C(O)c2ccc(N(C)C)cc2)cc1</smiles>

4, 4-bis ( N, N-dimethylamino ) benzophenone (Michlers's ketone)<smiles>C=C(C(=O)OC)N(C)C</smiles>

$\mathbf{N}, \mathbf{N}$-dimethylamino methacrylate<smiles>C=C(C)C(=O)OCCN(C)C</smiles>

Amines which may polymerize

copolymerize, and/or crosslink

during photoirradiation in

the presence of ketones

(photoinitiators) 


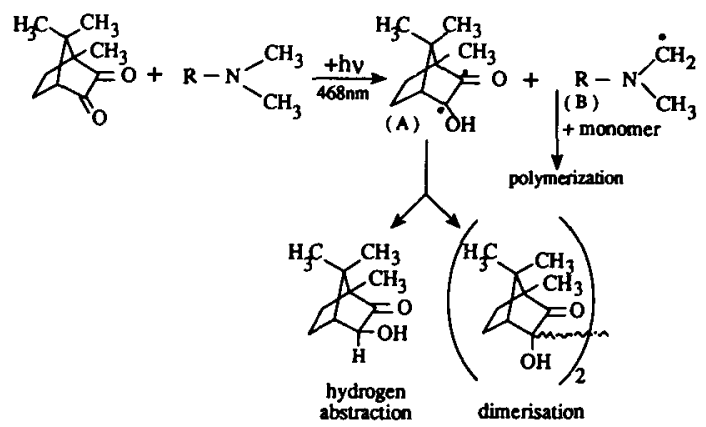

Scheme 1. Camphorquinone pinacol radical $(A)$ is deactivated by hydrogen abstraction and/or dimerisation reaction and cannot initiate polymerisation, whereas the amine radical (B) is responsible for the initiation of polymerisation.

Many other diketones (table 2) could be considered as photoinitiators, because of their extended absorption in the region $400-500 \mathrm{~nm}$. Most of them, however, are toxic and mutagenic and are not acceptable for application in dental photocuring.

Camphorquinone irradiated with light at $470 \mathrm{~nm}$ does not give free radicals which would initiate polymerization of monomers with unsaturated double bonds (e.g. methacrylates and their analogues). The presence of coinitiators with tertiary amine groups $-\mathrm{NR}_{2}$ (where $\mathrm{R}=\mathrm{CH}_{3}, \mathrm{CH}_{2} \mathrm{CH}_{3}$ ) is a condition for the formation of the reactive amino radical $\mathrm{NCH}_{2}$ in reaction with excited triplet state $(T)$ of camphorquinone (reaction 1). The hybrid photoinitiator system camphorquinoneamine e.g. $\mathrm{N}, \mathrm{N}$-dimethylaminoethyl methacrylate is very sensitive to light at $470 \mathrm{~nm}$. Changes of spectra of this hybrid photoinitiating system under light irradiation are shown in figure 2.

The reactions (2) are responsible for the decreasing absorption spectra of camphorquinone. One of the most effective bybrid systems is mixture of camphorquinone with Michler's ketone $\left(4,4^{\prime}\right.$-bis $(\mathrm{N}, \mathrm{N}$-dimethylamino) benzophenone). The latest one is itself a very active photoinitiator (Rabek 1987). However, it does not absorb light in the visible range $>400 \mathrm{~nm}$. Michlers ketone is, as are many other low molecular amines such as $\mathrm{N}, \mathrm{N}$-dimethyl-p-toluidine, toxic and mutagenic, and therefore not acceptable for application in intra-oral curing procedures. In spite of this very important toxicological problem, many companies use $\mathrm{N}, \mathrm{N}$-dimethyl-p-toluidine as a coinitiator.

In our laboratory we are working on hybrid photoinitiating systems, in which coinitiators (amines) are polymerized into homopolymers, or copolymerize with monomers used in composite restorative systems. Polymers with amine groups are almost non-toxic in comparison with low-molecular amines.

One such system is a hybrid formed from camphorquinone and $\mathrm{N}, \mathrm{N}$-dimethylaminoethyl methacrylate which after irradiation with light at $480 \mathrm{~nm}$ initiates polymerization of other methacrylic mono-, di- and tri-functional monomers, but also causes polymerization of amine methacrylate itself (figure 3). The kinetics of photopolymerization of $\mathrm{N}, \mathrm{N}$-dimethylaminoethyl methacrylate in the presence of camphorquinone is shown in figure 4.

This system has a rather long induction period and low conversion efficiency (maximum $75 \%$ ). The length of the inhibition period depends on the concentration of the inhibitor e.g. p-hydroquinone (ca. $0.1 \%$ ) and initial oxygen concentration. For practical application of this photoinitiator hybrid system in dental composites, the 


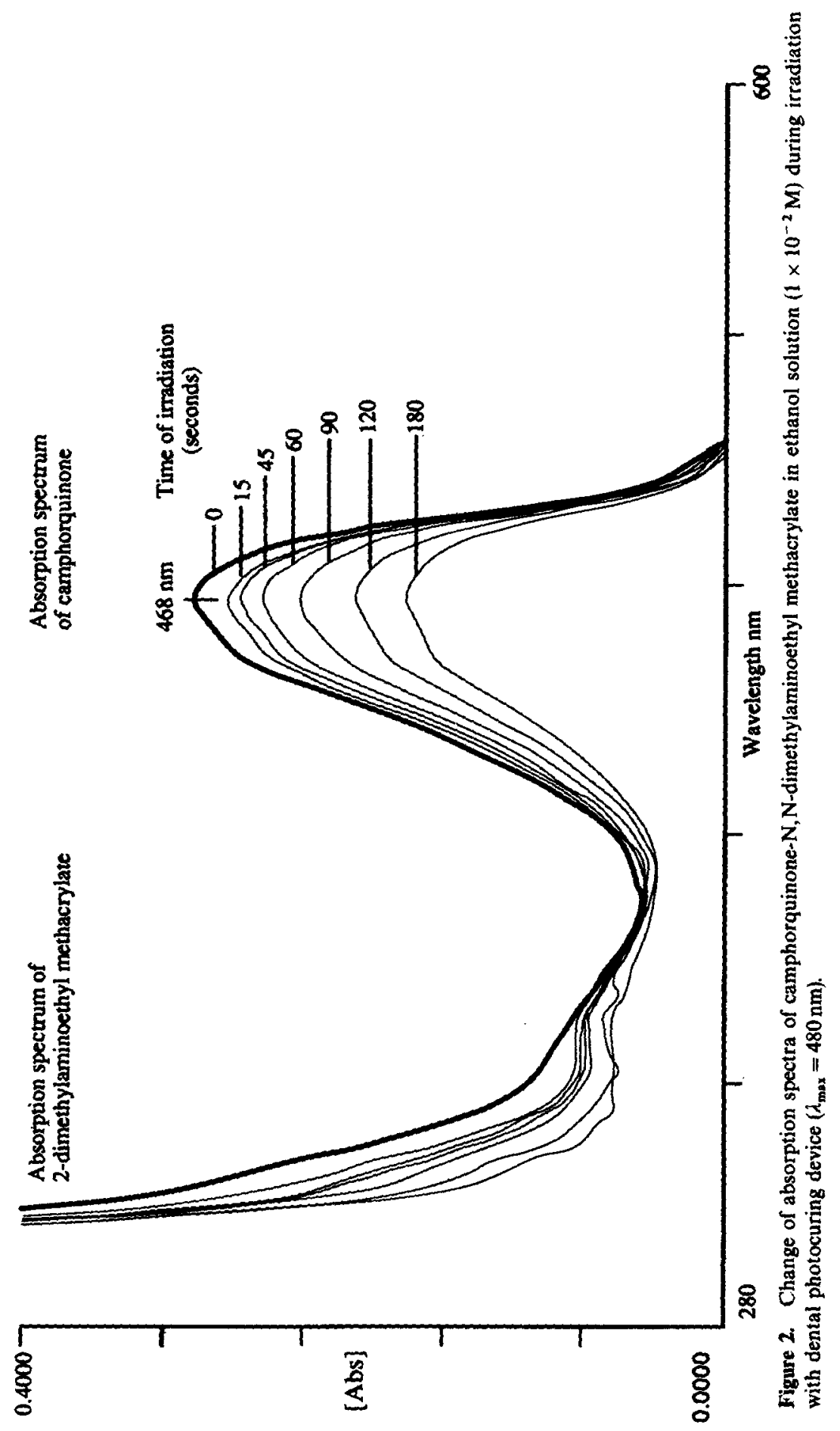



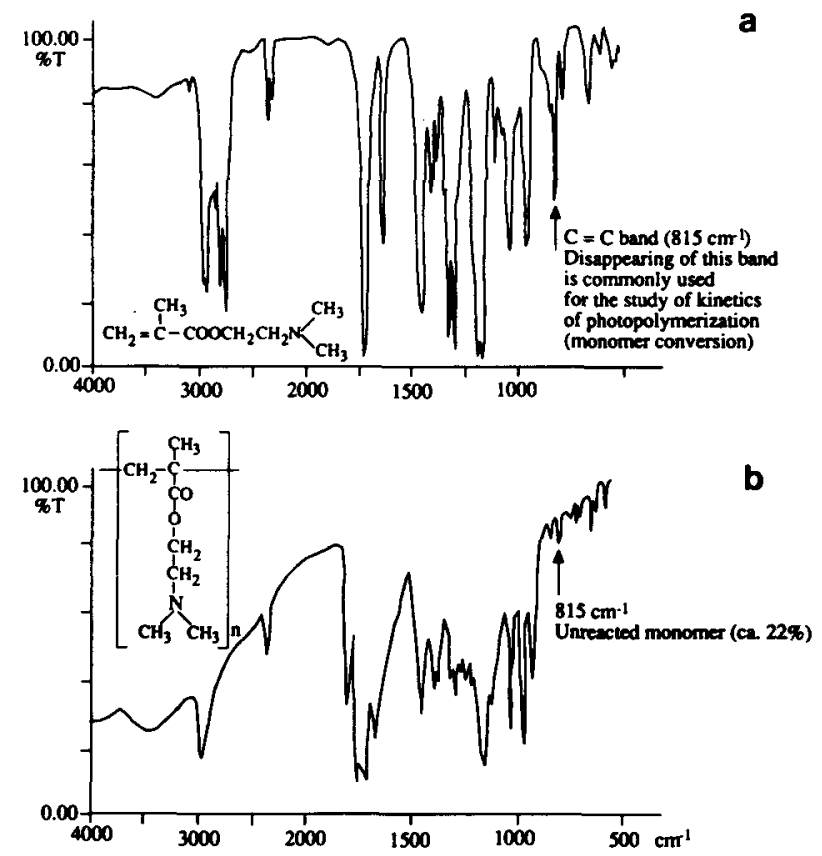

Figure 3. FTIR spectra of (a) pure $\mathrm{N}, \mathrm{N}$-dimethylaminoethyl methacrylate and (b) poly $(\mathrm{N}, \mathrm{N}$-dimethylaminoethyl methacrylate) obtained after $10 \mathrm{~min}$ light irradiation in the presence of camphorquinone.

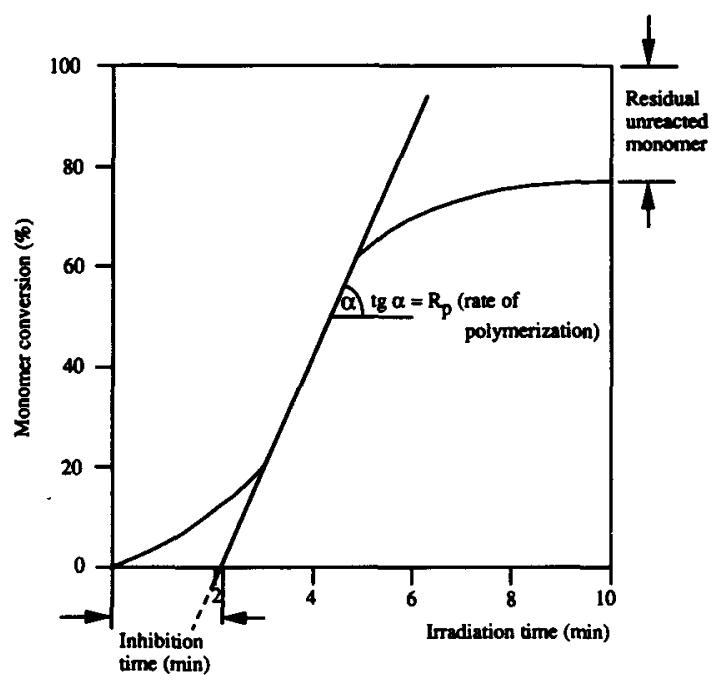

Figure 4. Kinetics of photopolymerization of 2-dimethylaminoethyl methacrylate in the presence of camphorquinone, determined from decreasing absorption of $\mathrm{C}=\mathrm{C}$ band at $815 \mathrm{~cm}^{-1}$ (FTIR).

presence of inhibitors is necessary to avoid prepolymerization. During the inhibition period, oxygen is consumed by the amino-radicals that have been formed. However, a very thin surface layer of monomer which is in contact with air remains unpolymerized. The thickness of the unpolymerized layer is dependent on the concentration of 
camphorquinone. At a ratio 1:10 of camphorquinone to amine, even the upper surface layer is polymerized. A higher intensity of light also decreases the induction period because the rate of radical formation is much higher.

Photocuring reactions occur, however, in much more complicated systems, depending on the type of dental formulation, which consist of different components:

(i) a mixture of monomers (mono-, di-, tri-functional oligomers), which differ in viscosities, initiation reactivities, propagation and termination reactions;

(ii) photoinitiator (systems) with different efficiencies of photofragmentations into free radicals or hydrogen transfer reactions producing active free radicals. Free radicals that are formed have differing reactivities with the monomers used in the initiation step, and they also participate in side reactions, e.g. deactivation, dimerisation, hydrogen abstraction, termination of polymerization propagation reactions, reactions with oxygen, and polymerization inhibitors;

(iii) additives such as prepolymerization inhibitors (used for storage stability), light stabilizers (against colour change of polymerized sample and to protect against its photodegradation);

(iv) reinforcing phase (fillers) such as silanized quartz, fused borosilicate and aluminosilicate glasses, silicon nitride, calcium silicate, calcium phosphates, aluminium oxide, ceramics, or hybrid fillers (e.g. prepolymerized resins with fumed or pyrogenic silica), which constitute the dispersed phase $(50-85 \%)$, limits the approach of light to the cured layers,

(v) coupling agents (as interface on the filler particles) usually 3-methacryl-oxypropyltrimethoxysilane.

Dental pit and fissure sealants, bonding agents, or orthodontic adhesives have similar zompositions, except that they are unfilled or lightly filled materials. Dental zomposites are used as two-component formulations, e.g. powder-liquid, paste-paste or as uniform paste.

Photoinitiated polymerization (photocuring) must often proceed in the oral cavity e.g. in conservative dentistry when filling cavities in teeth) within $20-40$ seconds, but should never exceed one minute. The main problem is the limited depth of polynerization (figure 5) and low conversion efficiency (maximum $75 \%$ ) (figure 6). The ow conversion efficiency can be the result of different causes

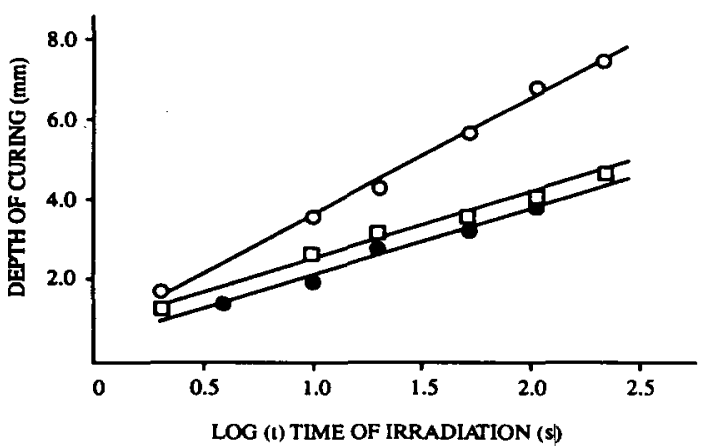

Figure 5. Depth of curing for different polymethacrylic compositions as a function of time of irradiation (Qvist et al 1990). 


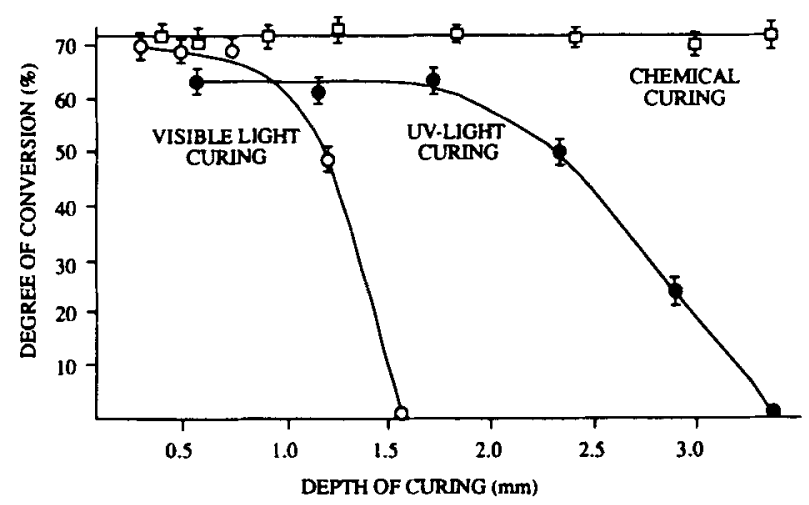

Figure 6. Comparison of degree of conversion at different depths of curing from the surface using different radiation sources with a chemical curing system (Ruyter and Sjövik 1981).

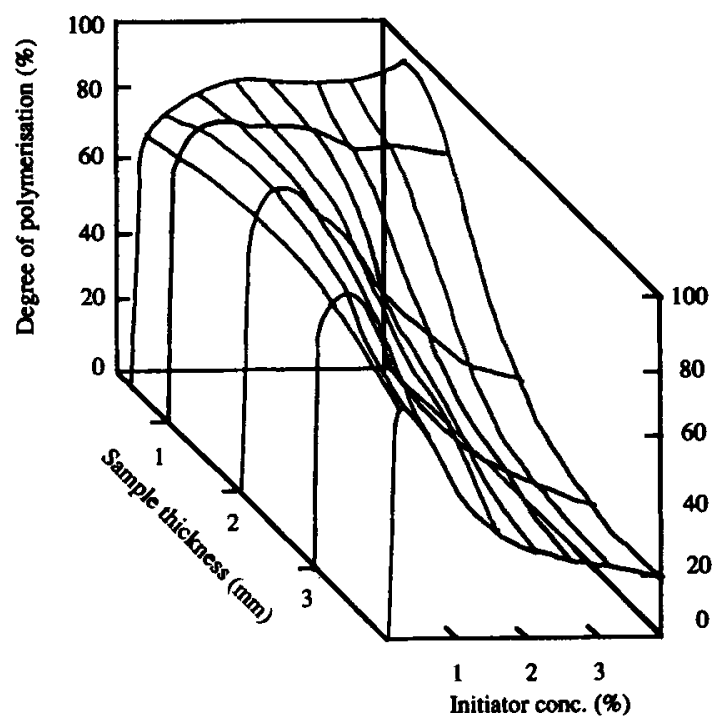

Figure 7. Degree of polymerization (degree of conversion in $\%$ ) as a function of sample thickness (mm) and initiator concentration (wt \%) (Guthrie et al 1986).

(i) Low radical concentration, low radical initiation effectiveness, sample thickness (figure 7) (Guthrie et al 1986). For example, increasing the initiator concentration from 1 to $5 \%$ can decrease the amount of unreacted monomer molecules from 22 to $8 \%$ (Decker and Mousa 1990);

(ii) increase of viscosity during the propagation and on reaching gel point, which restricts the mobility of propagating radicals;

(iii) termination reactions.

At low degrees of conversion (about $70 \%$ in most dental formulations), the final cured product contains unreacted monomer in addition to low molecular products of photolysis of photoinitiator and other organic additatives (inhibitors, stabilizers). All these components are distributed in a polymer cross-linked three-dimensional matrix network. 
A severe problem in the application of polymeric materials is the shrinkage of polymerizing formulations, which should not exceed $0 \cdot 2-2 \%$. Shrinkage, which is a result of volume change, causes a decrease in the dimensions of the final product, i.e. thickness of the sample layer. As a result of shrinkage, a gap is formed between the wall of the cavity and the filling material. This gap is easily accessible to food debris and microorganisms, which can cause secondary caries.

The shrinkage that occurs during polymerization arises from different causes.

(i) The major factor relates to the fact that monomers are located at Van der Waals' distances from one another, while in the corresponding polymer the (mono)mer units have moved to within a covalent radius which is approximately $1 / 3$ Van der Waals' radius. This causes the shrinkage that is roughly related to the number of mono(mer) units per unit volume that is converted to polymer.

(ii) The change in entropy and the relative free volumes of monomer and polymer. Free volume is primarily determined by the packing efficiency of the macromolecules. Crystalline (and to some extent semi-crystalline) polymers are, for example, more closely packed than the corresponding amorphous polymers.

Thus crystalline monomers will shrink less than noncrystalline (liquid) monomers. In the case of methacrylate monomers it is impossible to avoid shrinkage (which ranges up to $10 \%$ ).

Only polymerization with expansion in volume can solve this problem (Cook 1980). In this type of polymerization, expansion in volume can be achieved through a ring-opening process, wherein two bonds are cleaved for each new bond formed giving a polymer with a volume shrinkage of 1.4-1.7\% (Thompson et al 1979). The free-radical ring-opening polymerization of a 2-methylene spiro orthocarbonate monomer can be initiated by the hybrid photoinitiator system camphorquinone-(4$\mathrm{N}, \mathrm{N}$-dimethylaminobenzoate) and occurs by the following mechanism (Stansbury 1992) (scheme 2).

The resulting expansion can be applied to counteract the polymerization shrinkage associated with the conventional methacrylate monomers used in dental composites, and thereby provide formulations with drastically reduced shrinkage (Thompson et al 1979).

Shrinkage causes not only volumetric and dimensional changes but also builds up large stresses within the material. A variety of material deficiences has been attributed to the volume contraction associated with the polymerization of dental resins in composites for clinical applications. These deficiencies arise from the generation of stresses which are of sufficient magnitude to cause defects within the resin matrix, and debonding at the surface (Feilzer et al 1987, 1990; Zindan et al 1987). These complications weaken performance and often restrict those situations for which composites and other related dental resin materials can be considered.

Applications of photocured dental composites in the oral cavity bring several other problems.

(i) In a photocured polymer formulation there can exist trapped radicals, which have relatively long lifetimes at room temperature. The lifetime of free radicals can exceed five months when certain dimethylacrylates (such as 1,6-hexanediol diacrylate and bis(2-hydroxyethyl acrylate bisphenol-A dimethacrylate) are polymerized (Klooserboer et al 1984). The presence of free radicals in a dental 

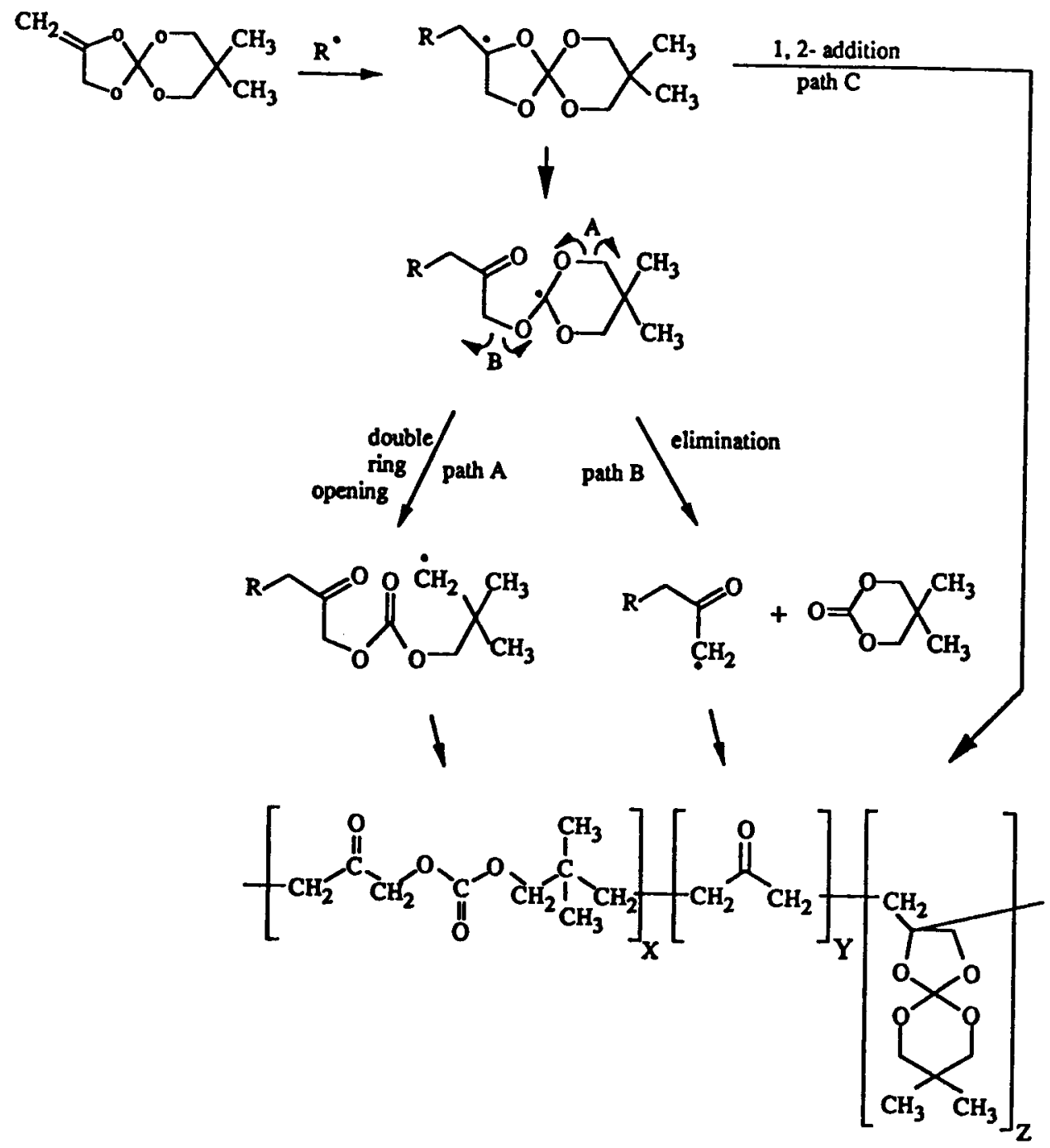

Scheme 2.

composite material in contact with oral soft tissues might cause genetic changes (a problem which has not been investigated yet).

(ii) Unreacted monomer and other low-molecular (non-polymerized) (Ruyter and Svendsen 1978; Söderholm 1983; Lindén et al 1993) components gradually diffuse out of the matrix because they are not compatible with the polymer matrix. They are removed from the surface of filling material by wear or are dissolved and/or transported with saliva to the intestine, where these substances (e.g. poly(acrylic acid)) (Cook 1982) can be absorbed and distributed in the body (Lindén 1991).

Some of these substances can be toxic to pulp and surrounding mucous membranes, and can also cause allergic reactions. It is well known that all methacrylic monomers are toxic (much less than acrylic), whereas amines, together with their high toxicity, are mutagenic and can also cause allergic reactions. Little is known about the toxicity and allergenity of low molecular products of 
fragmentation of photoinitiators (not attached to polymer chains). On the other hand, polymers, especially cross-linked ones, are non-toxic but their allergenic and mutagenic effects are still not well known. It has been observed that many patients and dental personnel show allergic reactions in connection with restorative dentistry using polymeric materials.

(iii) Chemical and biodegradation of photocured dental composites in the oral cavity. This mode of degradation is caused by rapid changes of $p \mathrm{H}$ in the oral cavity (bases and acids present in food), oxidation processes in which oxygen is involved (from air and dissolved in liquids and present in food), and fermentation processes in which acid is produced. These hydrolytic and oxidative degradations cause de-esterification processes, formation of $\mathrm{OH} / \mathrm{OOH}$ groups, and chain scission and cross-linking processes. Many polyacrylic materials are susceptible to biodegradation and enzymatic hydrolysis (Munksgaard and Freund 1979) caused by microorganisms such as bacteria and fungi.

(iv) Photocured dental composites are also exposed to often rapid thermal changes (from $-70^{\circ}$ to $+70^{\circ} \mathrm{C}$ ) in the oral cavity. Typical damage due to such forces is the formation of microcracks, cavities, and a rough and corrugated surface. Saliva and fluid foodstuffs may also cause hydrodynamic damage to the surface and participate in the removal of material (figure 8). Such damaged surfaces serve as retentive areas for food debris, bacterial plaque, and discolorations. Finally, polymeric materials become brittle and numerous surface microcracks render them less resistant to mechanical wear, and surface layers are thus removed.

The lifetime for anterior polymeric restorative materials is about 8 years, but for posterior (fillings attaining loads) it is often not longer than 2-4 years (Qvist et al 1990). Most polymeric materials used as restoratives must be repaired and polished during this time. Traditional restorative materials for posterior teeth are dental amalgams with very long lifetimes (10-20 years). In the last decade, questions about mercury release from fillings and a growing social concern about metal toxicity has raised serious doubts about using amalgams. This has led to the necessity of replacing amalgams by non-toxic materials, e.g. polymeric composite resins. In comparison with dental amalgam fillings with lifetimes exceeding 10 years, polymeric materials are, however, still inferior.

Another very important group of polymeric dental materials are polyionomer cements based on poly(acrylic) or other polycarboxylic acid analogues and inorganic glass materials (aluminosilicates) (Wilson and McLean 1988). Carboxylic groups present in poly(acrylic acid) form, with aluminosilicate glasses, very strong coordination complexes which are bonded to various substrates such as dentin, enamel, and several metallic materials.

Despite the many advantages of polyionomers used for dental applications (high biocompatibility, good adhesion to enamel, dentin and metallic restorations), they are easily hydrolysed by acids. In order to improve the hydrolytic degradation properties of polyionomer cements, blends with difunctional monomers and/or its copolymers with monomers having functional double bonds (remaining after copolymerization) are used instead of pure poly(acrylic acid). These polyionomers are further photocured in the presence of aluminosilicate glasses. Such cross-linked polymeric networks (figure 9) protect coordination bonds against acids that cause their hydrolytic decomposition and improve their dimensional tensile strength. 


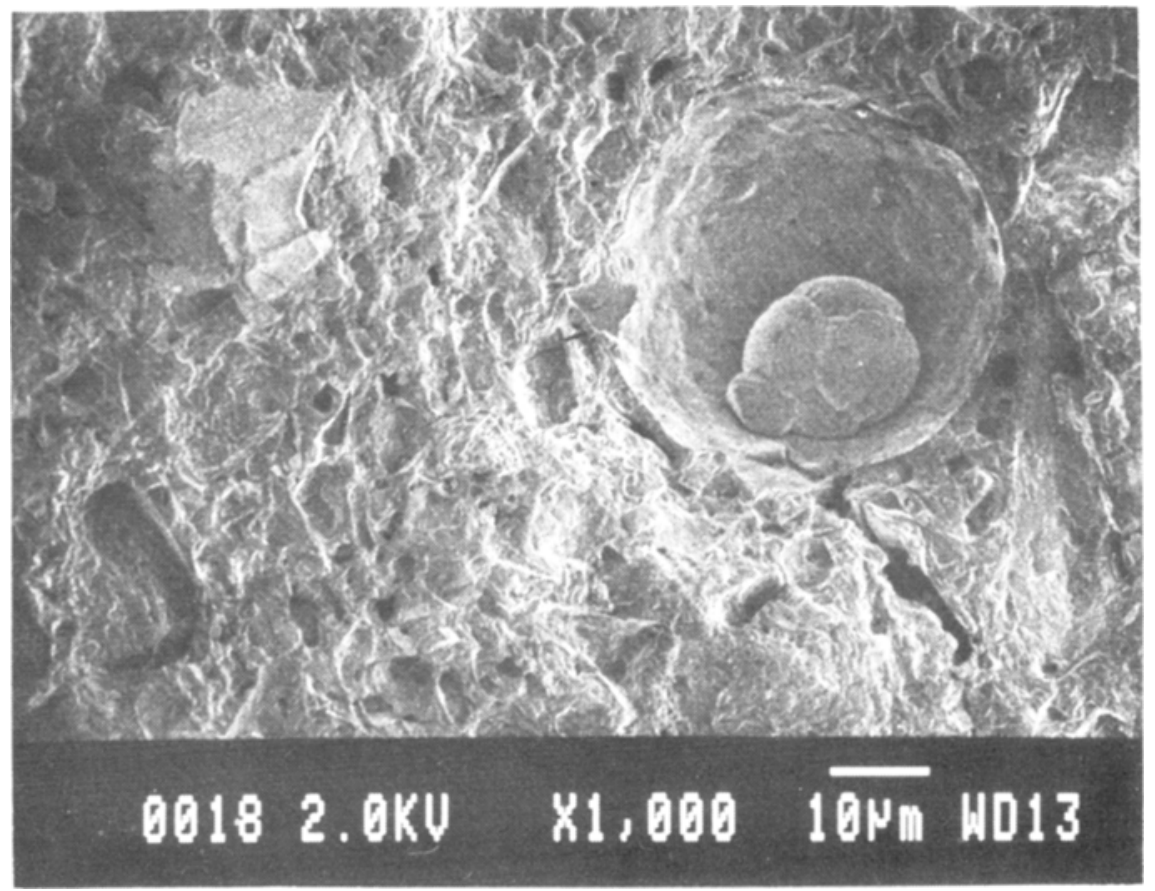

Figure 8. SEM micrograph of surface of photocured dental glass-inomer cement after exposure in an oral environment for 120 days (Lindén et al 1993).
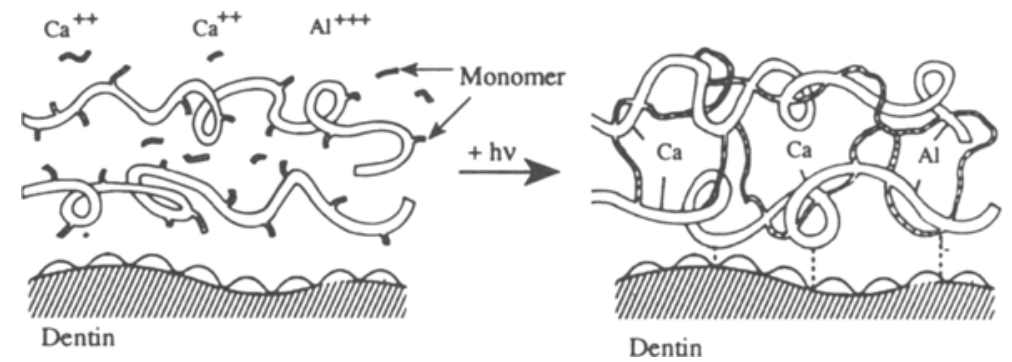

Figure 9. Photopolymerization and formation of coordination complexes in glass-ionomers.

Poly(acrylic acid) also forms ionic complexes with a number of metallic salts e.g. $\mathrm{FeCl}_{3}$ giving a hydrogel (Lindén and Rabek 1993), which was used for tightening micro-channels in human dentine (figure 10 ) in order to block transportation of toxins and bacteria to the underlying pulp tissue.

In order to decrease hydrolytic degradation of these ionic complexes, it is possible to photocross-link them with mono- and difunctional monomers, e.g. N,Ndimethylaminoethyl methacrylate in the presence of camphorquinone. Free carboxylic groups $(-\mathrm{COOH})$ that do not participate directly in formation of ionic complexes with $\mathrm{FeCl}_{3}$ can react with amine groups $\left(-\mathrm{NR}_{2}\right)$ :

$$
-\mathrm{COOH}+-\mathrm{NR}_{2} \rightarrow-\mathrm{COOH}^{-} \mathrm{H}^{+} \mathrm{R}_{2} \mathrm{~N}-\text {. }
$$




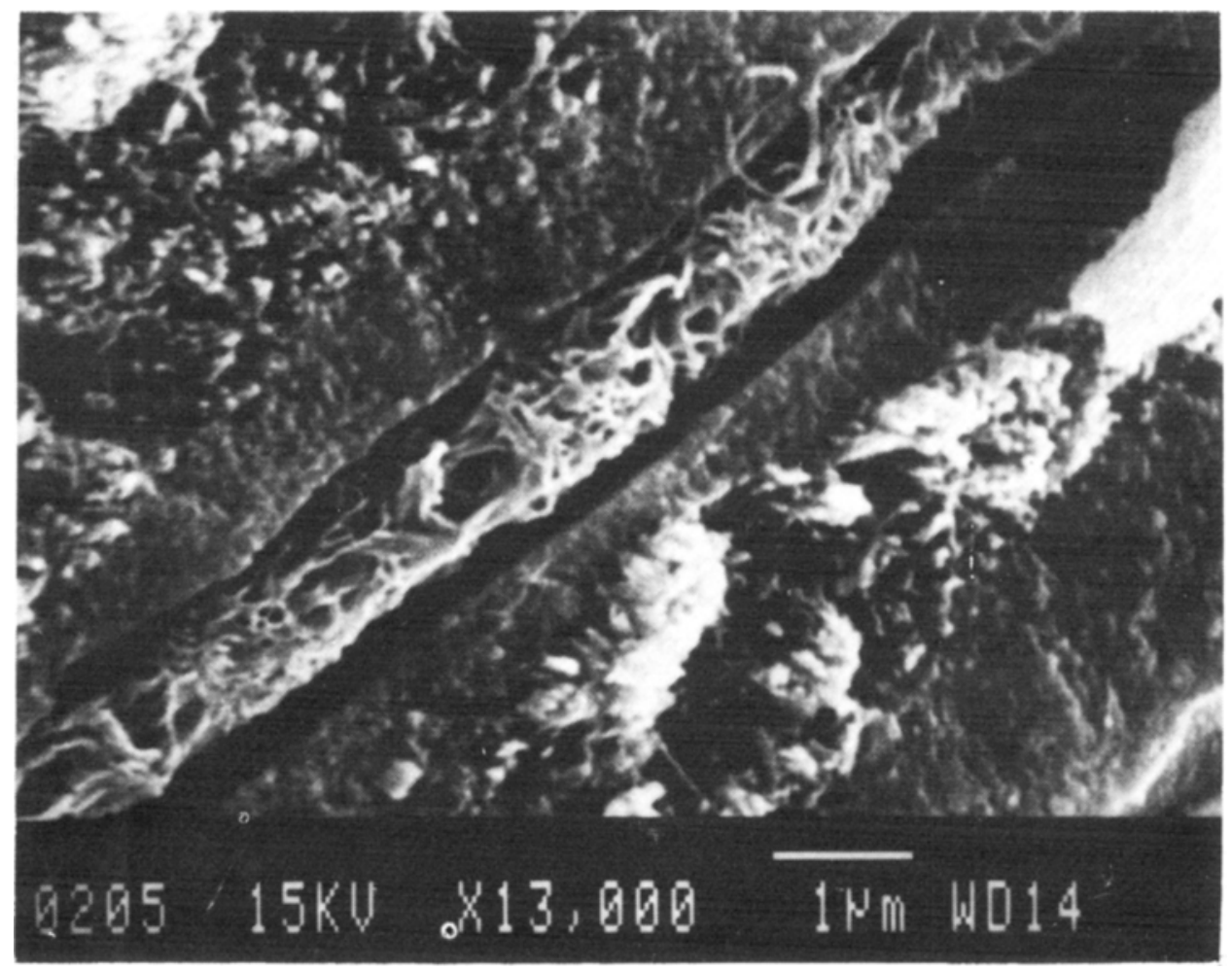

Figure 10. SEM micrograph of human dentin with tubule (micro-channel) blocked by a complex formed between polycarboxylic acid and $\mathrm{FeCl}_{3}$ (Linden and Rabek 1993).

In this way a three-dimensional cross-linked network is formed that consists of both covalent (from photocuring) and ionic bonds, and is resistant against hydrolytic degradation.

In conclusion, there are no "ideal" polymeric dental materials yet available that could replace the unique properties of the "old" amalgam-filling materials. It is necessary to search for new monomers with a high degree of conversion, which can give a polymer with very low shrinkage, and which could be resistant to all types of degradation processes that occur in the oral cavity. It is also important to synthesize fluoromonomers, which during degradation processes could release fluoride to decrease the risk of secondary caries.

However, synthetization of monomers and production of new materials for dental applications should be accompanied by careful testing of their ageing in an oral environment and for release of substances that may have toxicological and allergiological implications in their use. Our institute is currently engaged in researching these problems.

\section{References}

Birdsell D C, Bannon P J and Webb R B $1977 \mathrm{~J}$. Am. Dent. Assoc. 94311

Cook W D 1980 J. Dent. Res. 59800 
Cook W D 1982 J. Dent. Res. 611436

Cook W D 1992 Polymer 33600

Decker C and Mousa K 1990 Makromol. Chem. 191963

Dietliker K 1991 In Chemistry and technology of UV and EB formulation for coatings, inks and paints (ed.)

P K T Oldring (London: SITA Technology) p. 267

Feilzer A J, De Gee A J and Davidson C L 1987 J. Dent. Res. 661636

Feilzer A J, De Gee A J and Davidson C L 1990 Dent. Mater. 6167

Guthrie J, Jeganathan M B, Otterbrun M S and Woods J 1986 Polym. Bull. 1551

Klooserboer J E, Van der Hei G M M, Gossinkad R G and Dortant M C G 1984 Polym. Commun. 25322

Lindén L $\AA$, Morge S and Adamczak E 1993 Swed. Dent. J. (in press)

Lindén L $\AA$ and Rabek J F 1993 J Appl. Polym. Sci. (in press)

Munksgaard E C and Freund M 1979 Scand. J. Dent. Res. 98261

Qvist V, Qvist J and Mjör I A 1990 Acta Oddontol. Scand. 48305

Rabek J F 1987 Mechanisms of photophysical processes and photochemical reactions in polymers (Chichester Wiley) p. 297

Ruyter I E and Sjövik I J 1981 Acta Odontol. Scand. 39133

Ruyter I E and Svendsen S A 1978 Acta Odontol. Scand. 3675

Sheela M S, Selvy K T, Krishan V K and Paul S N 1991 J. Appl. Polym. Sci. 42561

Söderholm K J 1983 J. Dent. Res. 62126

Stansbury J W 1992 J. Dent. Res. 711408

Thompson V, Williams E F and Bailey W J 1979 J. Dent. Res. 581522

Wilson A D and McLean J W 1988 Glass ionomer cement (Chicago: Quintessence Book)

Zindan O, Gomez-Martin O and Tsuchiya T 1987 J. Dent. Res. 66716 